Retrospectiva/Overview

\title{
A Investigação em Fonologia do Português
}

(Research in Portuguese Phonology)

\author{
Maria Helena Mira Mateus \\ (Universidade de Lisboa)
}

\begin{abstract}
This paper is an overview of the phonological studies in Portuguesestarting with the formal analyses developed in Portugal after the publication of The Sound Pattern of English (1968). The relevant works on European Portuguese published before Chomsky $\sigma$ Halle are included in the Introduction: the most important dialectal and philological works, phonetic studies as well as structural descriptions. Formal analyses are divided in two parts: those that follow standard generative phonology and those oriented by subsequent theories. The annex includes a comprehensive bibliography of all phonological books and papers published in Portugal after the seventies.
\end{abstract}

KeY-Words: Phonology; Formal Analyses; Autosegmental Phonology; Feature Geometry; Underspecification; Lexical Phonology.

RESUMO: Neste artigo pretende-se traçar uma panorâmica dos estudos de fonologia realizados em Portugal, com especial incidência nas análises formalizadas que se desenvolveram a partir da obra de Chomsky e Halle (1968). Na Introdução referem-se obras que marcaram a fonologia do Português Europeu antes dessa data, e apresentamse os principais trabalhos de carácter dialectal e filologico, os estudos fonéticos e as obras que se integram na linguistica estrutural. Na apresentação das análises formais distingue-se a fonologia generativa clássica das teorias que lhe sucederam $O$ artigo tem um anexo que contém a bibliografia exaustiva dos livros eartigos publicados em Portugal a partir dos anos 70 .

PaLAVRAS-CHAVE: Fonologia; Análises Formais; Fonologia Auto-segmental; Geometria de Traços; Subespecificação; Fonologia Lexical. 


\section{Introdução ${ }^{1}$}

Os actuais linguistas portugueses herdaram, dos filólogos e linguistas que os precederam, um espólio de grande riqueza que incidia, sobretudo, na história da língua portuguesa e na identificação das características do português antigo, na dialectologia e na descrição das peculiaridades dialectais. Em todos estes domínios o estudo dos sons foi sempre privilegiado. Recorde-se que na primeira gramática portuguesa, Fernão de Olivei$\mathrm{ra}^{2}$ consagra 23 dos 50 capítulos da obra à análise dos sons e das letras, e que nas gramáticas surgidas entre os séculos 16 e 19 a ortografia, a ortoepia e a prosódia têm lugar de destaque principalmente com objectivos normativos e pedagógicos ${ }^{3}$.

A primeira descrição de conjunto do sistema fonético do português surge em 1883, no estudo de Aniceto dos Reis Gonçalves Viana ${ }^{4}$ com um título que inclui já o termo fonologia: "Essai de phonétique et de phonologie de la langue portugaise d'après le dialecte actuel de Lisbonne". Esta e as obras que se seguem do mesmo autor são ainda hoje de importância indiscutível para o conhecimento do sistema fonológico do português. A partir do início do século 20 a influência dos neogramáticos reconhece-se no surgimento de gramáticas históricas, hoje clássicas, como as de José Joa-

\footnotetext{
${ }^{1}$ Sendo objecto deste artigo uma perspectiva da investigação que actualmente se produz em Portugal sobre fonologia do português, condensei na Introdução as referências aos seguintes vertentes que incidem sobre o nível fonético da língua:

I. - a tradição filológica e histórica e a sua continuação em trabalhos de autores contemporâneos; II. - a actividade desenvolvida até ao presente na área da dialectologia;

III. - as análises experimentais de fonética articulatória e acústica

A obra de Morais Barbosa, referida igualmente nesta Introdução, precede a investigação integrada na teoria generativa que será apresentada nas secções seguintes.

${ }^{2}$ Fernão de Oliveira, Grammatica da lingoagem portuguesa. Lisboa: e[m] casa de Germão Galharde, 1536. (3a ed. preparada por Rodrigo de Sá Nogueira. Lisboa: Ed. de José Fernandes Júnior, 1933. Ver também João de Barros, Grammatica da Lingua Portuguesa. Lisboa: Luis Rodrigues, 1540.

${ }^{3}$ Jorge de Morais Barbosa no primeiro capítulo dos Études de Phonologie Portugaise (1965) refere o carácter normativista e de preocupação ortográfica destas primeiras gramáticas, mas observa que por vezes os seus autores, não sendo foneticistas, "são 'fonólogos' que nos deixaram, através do estudo das letras, elementos importantes para o conhecimento do sistema do português da sua época".

${ }^{4}$ A. R. Gonçalves Viana. "Essai de phonétique et de phonologie de la langue portugaise d'après le dialecte actuel de Lisbonne". Romania, t. XII, Paris, 1883. Ver ainda a "Exposição da pronúncia normal portuguesa para uso de nacionais e estrangeiros". Ambos os trabalhos foram republicados em Estudos de Fonética Portuguesa, Lisboa: Imprensa Nacional, 1973, 83-152 e 153-257.
} 
quim Nunes ${ }^{5}$ e de Edwin Williams ${ }^{6}$, em que a fonética/fonologia da língua portuguesa são tratadas na sua evolução histórica com referência, por vezes, a aspectos dialectais particulares.

Estas obras e as congéneres estrangeiras sobre as línguas românicas foram a fonte de muitos trabalhos que vieram a lume durante o século 20 sobre questões parcelares do nível fonético do português. Nesta linha se situam vários estudos de Luís Lindley Cintra ${ }^{7}$ e Herculano de Carvalho ${ }^{8}$, para citar apenas alguns autores de entre uma plêiade de filólogos portugueses que nos deram a conhecer aspectos da formação e desenvolvimento da fonética da língua portuguesa. ${ }^{9}$ Os estudos de filologia mantiveram-se até ao presente nas Universidades de Lisboa e Coimbra, com relevo para a investigação desenvolvida por Ivo Castro, Ana Maria Martins e Clarinda de Azevedo Maia. ${ }^{10}$

Relativamente a uma descrição sincrónica do português, até meados do século 20 o estudo dos dialectos prevaleceu sobre o estudo do sistema fonológico. Nesse campo, na esteira de Leite de Vasconcelos ${ }^{11}$ destaca-se a imensa recolha de falares portugueses dinamizada e orientada em Coimbra

\footnotetext{
${ }^{5}$ José Joaquim Nunes. Compêndio de gramática histórica portuguesa. Lisboa: Livraria Clássica Editora, 1919 (6.a ed. Lisboa: Clássica Editora. 1959).

${ }^{6}$ Edwin B. Williams Latin to Portuguese. Historical phonology and morphology of the portuguese language. Philadelphia: University of Pennsylvania, 1938. (Trad. part. de A. Hauaiss: Do Latim ao Português. Fonologia e morfologia históricas da língua portuguesa. Rio de Janeiro: MECIINL, 1961.) ${ }^{7}$ Ver, sobretudo, A linguagem dos foros de Castelo Rodrigo, seu confronto com a dos foros de Alfaiates, Castelo Bom, Castelo Melhor, Coria, Cáceres e Usagre. Contribuição para o estudo do leonês e do galego — português do século XIII. Lisboa: Centro de Estudos Filológicos, 1959 e "Apport des anciens textes romans nonlittéraires à la connaissance de la langue du Moyen Âge". Revue de Linguistique Romane, xxvvii, Paris, 1963.

${ }^{8}$ Refiro-me, em especial, ao importante artigo "Valor dos grafemas e e o em sílaba átona", publicado na Revista Portuguesa de Filologia XII, Coimbra, 1862-63.

${ }^{9}$ Tratando este texto do desenvolvimento da fonologia em Portugal, os autores brasileiros não são indicados, nem nesta introdução nem na apresentação mais extensa da actual situação da investigação nesse domínio. No entanto, não posso deixar de referir aqui os nomes de Serafim da Silva Neto, Said Ali e Celso Cunha, a quem devemos trabalhos fundamentais para o conhecimento da história da língua portuguesa.

${ }^{10} \mathrm{Na}$ bibliografia em anexo estão indicados os três autores aqui citados e as obras de interesse para o objectivo deste artigo.

${ }^{11}$ Ver em especial a tese de doutoramento apresentada à Universidade de Paris em 1901: Esquisse d'une dialectologie portugaise. Segunda edição de Maria Adelaide Valle Cintra. Lisboa: Centro de Estudos Filológicos, 1970.
} 
por Manuel de Paiva Boléo ${ }^{12}$ e, em Lisboa, a actividade estimulante de Luís Lindley Cintra ${ }^{13}$ com a realização de estudos parcelares de dialectologia e do traçado de um panorama global das grandes áreas dialectais galegoportuguesas. A dialectologia mantém-se com grande vivacidade em Portugal, tanto na Universidade de Coimbra como na de Lisboa ${ }^{14}$.

Mas por volta dos anos 50 os estudos fonéticos sobre o português revelam já a intenção de descrição das características da língua contemporânea dos seus autores. No campo das análises experimentais de fonética acústica, o trabalho desenvolvido em Coimbra, até aos anos 70, pelo foneticista Armando de Lacerda foi seguido, em Lisboa, por Raquel Delgado Martins, e continuado por Maria do Céu Viana, Amália Andrade e Fernando Martins ${ }^{15}$.

As análises realizadas, e que ainda hoje evidenciam grande vitalidade, mostram uma preocupação de interpretação linguística e têm contribuído para o conhecimento da fonologia do português. São de destacar os trabalhos sobre os segmentos fonológicos de Maria do Céu Viana, Amália Andrade, Raquel Delgado-Martins e Isabel Mascarenhas. Incluem-se também na perspectiva de fonética experimental, com consequências interessantes para a fonologia, os trabalhos de Raquel Delgado Martins sobre o acento de palavra e as teses de mestrado de Maria João Freitas sobre pausas, de Isabel Mata da Silva sobre interrogação e de Fernando Martins sobre entoação e organização do enunciado, a que se sucedeu a sua tese de doutoramento sobre um modelo de reconhecimento da fala para a língua portuguesa. A investigação em sintese da fala, desenvolvida em equipa por investigadores de inteligência artificial e de linguística está presentemente em curso e tem obtido resultados notáveis. ${ }^{16}$

\footnotetext{
${ }^{12}$ Cito aqui apenas o "Mapa dos dialectos e falares de Portugal Continental", feito em colaboração com Maria Helena Santos Silva e publicado no Boletim de Filologia, XX, Lisboa, 1962, que poderá levar a uma interessante comparação com a "Proposta" de Luís Cintra, indicada na note 12.

${ }^{13}$ Veja-se, principalmente, a "Nova proposta de classificação dos dialectos galego-portugueses", in Boletim de Filologia, XXII, 1971 e Estudos de dialectologia portuguesa, Lisboa: Sá da Costa..

${ }^{14}$ Refira-se o trabalho desenvolvido pelo grupo de dialectólogos do Centro de Linguística da Universidade de Lisboa na construção do Atlas Linguístico de Portugal e da Galiza (ALPG), e na colaboração desse mesmo grupo com investigadores europeus para a elaboração do grande Atlas da Europa (Atlas Linguarum Europae, ALE) e do Atlas Linguístico Românico.

${ }^{15}$ No anexo bibliográfico estão incluídos os autores aqui referidos e os respectivos trabalhos de fonética experimental que têm interesse para a análise fonológica..

${ }^{16}$ A investigação está a ser realizada no INESC e é conduzida, do ponto de vista linguístico, por Maria do Céu Viana.
} 
A descrição do sistema fonológico do português numa perspectiva estruturalista está presente, pela primeira vez, na obra de Jorge de Morais Barbosa Études de phonologie portugaise. ${ }^{17}$ Lembre-se que o estruturalismo estabeleceu desde o início, nos anos 30 , a distinção entre fonética e fonologia, distinção presente, sobretudo, nos trabalhos realizados no âmbito do Círculo Linguístico de Praga e nas obras dos estruturalistas americanos. Trubetzkoi, em 1939, definia a fonética como "a ciência da face material dos sons da linguagem humana" e a fonologia como o estudo que [...] "deve procurar que diferenças fónicas estão ligadas, na língua estudada, a diferenças de significação, como se comportam entre si os elementos de diferenciação (ou marcas) e segundo que regras podem combinar-se uns com os outros para formar palavras e frases" ${ }^{18}$ Bloomfield, em 1933, denomina fonologia (ou fonética prática) "o estudo dos sons significantes do discurso", afirmando que a fonologia "inclui a consideração do significado". ${ }^{19}$

As definiçōes destes dois autores de referência do estruturalismo linguístico mantiveram-se, como orientação, para a determinação dos elementos dos sistemas fonológicos muito para além de uma visão exclusivamente estruturalista. $\mathrm{Na}$ realidade, a investigação fonológica que se desenvolveu a partir de final dos anos 60 no quadro da teoria generativa não tem como objectivo discutir quais os elementos fónicos que fazem parte do sistema fonológico de uma língua. Preocupa-se antes com questōes relacionadas com a organização desses elementos, e com a representação das operaçōes do processamento mental na percepção e produção do nível fonológico da gramática, para o que constrói e selecciona instrumentos formais adequados.

\section{As primeiras análises formais ${ }^{20}$}

A obra de Chomsky e Halle The Sound Pattern of English, surgida em $1968^{21}$, constituiu o modelo para a elaboração de diversos trabalhos in-

\footnotetext{
${ }^{17} \mathrm{Na}$ introdução a esta obra o autor faz uma revisão criteriosa das primeiras gramáticas portuguesas e apresenta desenvolvidamente os trabalhos de Gonçalves Viana,considerados cuja intuição linguística permitia uma visão sistemática e fonológica dos sons do português.

${ }^{18}$ Nicolas Trubetzkoy. Principes de phonologie. Paris: Klincksieck, 1949, p. 12. Primeira edição em alemão, Grundzüge der Phonologie. Güttingen: Vandenhoeck \& Ruprecht, 1939.

${ }^{19}$ Leonard Bloomfield. Language. New York: Holt, Reinhart \& Winston, 1933, pp76-77 da edição francesa Le langage. Paris: Payot, 1970.

${ }^{20}$ Os autores referidos a partir desta secção e até final do artigo, e os respectivos trabalhos, estão incluídos no anexo bibliográfico.

${ }^{21}$ Noam Chomsky e Morris Halle. The sound pattern of English, New York: Harper and Row, 1968.
} 
tegrados na teoria generativa hoje denominada clássica ou standard, aplicando e testando no nível fónico das línguas os princípios dessa nova teoria da gramática.

Dentro desta perspectiva, o estabelecimento dos elementos do sistema fonológico no nível de superfície decorria da aplicação de métodos e técnicas do estruturalismo. Contudo, em obediência aos princípios teóricos da gramática generativa, toda a análise se orientava para a construção de um nivel subjacente relacionado com o de superfície através de regras, e com a formalização das generalizaçôes estipuladas. A proposta de hipóteses relativas a esse nível abstracto subjacente e a formulação das regras passaram então a ocupar lugar central nos estudos dos sistemas fonológicos, tendo como corolário as discussões sobre os traços distintivos do segmento fonológico. Evidentemente, as análises assim orientadas também procederam, em certos casos, à revisão dos elementos de um determinado sistema fonológico previamente estabelecidos com base no modelo estruturalista.

Complementarmente, e dentro dos mesmos pressupostos teóricos, a análise da variação fonológica dos paradigmas morfológicos foi considerada mais explicativa do que as anteriores descriçōes da morfologia das línguas. A partir desta época, e com base nas hipóteses formuladas pela teoria, discute-se igualmente a relação entre os mecanismos formais da gramática e os processos cognitivos subjacentes à actividade linguística. ${ }^{22}$

Várias línguas foram objecto de uma análise que seguiu de perto o padrão de Chomsky e Halle, como o francês na obra de Schane, o espanhol na obra de Harris e o italiano no trabalho de Saltarelli ${ }^{23}$. O português foi tratado dentro deste modelo nos Aspectos da Fonologia Portuguesa de Maria Helena Mira Mateus e na Phonologie (Générative) du Portugais de Ernesto d'Andrade Pardal. O mesmo enquadramento teórico subjaz a grande parte dos artigos publicados por Ernesto d'Andrade até inícios dos anos 90 e incluídos nos Temas de Fonologia. Integram-se também no modelo clássico da fonologia generativa os artigos publicados por Maria Helena Mateus até à mesma data e, ainda, os capítulos sobre Fonologia desta autora na Gramática da Lingua Portuguesa e na Introdução à Linguistica Gerale Portuguesa.

\footnotetext{
${ }^{22}$ Ver anexo bibliográfico.

${ }^{23}$ Sanford Schane. French Phonology and Morphology. Cambridge, Mass.: The MIT Press, 1968. James Harris, Spanish Phonology. Cambridge, Mass.: The MIT Press, 1969. Mario Saltarelli. A Phonology of Italian in a Generative Grammar. The Hague: Mouton, 1979.
} 


\section{A fonologia pós-SPE}

Nos estudos que imediatamente se seguiram à aplicação do modelo de Chomsky e Halle podemos distinguir as seguintes orientaçôes

1. Uma aproximação à 'realidade' dos sons, em reacção ao carácter abstracto das análises da fonologia generativa clássica, sob as denominações de fonologia natural e de fonologia generativa natural. Estes modelos não tiveram repercussão na investigação fonológica realizada em Portugal.

2. A formalização da variação nos sistemas fonológicos, com relevo para a teoria da variação. A influência deste modelo está presente em poucos trabalhos de linguistas portugueses ${ }^{24}$ : Ressalve-se, no entanto, a dissertação de doutoramento de Maria Celeste Rodrigues sobre fonologia e variação $\mathrm{o}^{25} \mathrm{em}$ que, a par da análise variacionista com base em dados quantitativos, se propõem regras fonológicas orientadas pela teoria autosegmental e pelo modelo da geometria de traços.

3. Uma análise métrica do acento com representação em diagrama arbóreo. Deve referir-se a análise do acento de palavra em português, realizada por Ernesto d'Andrade e integrada neste modelo ${ }^{26}$, uma proposta que não teve seguidores e que o autor substituiu mais tarde por uma análise com construção de grelha métrica, como se verá adiante.

4. A proposta da fonologia auto-segmental, com abandono do modelo linear da fonologia clássica em favor de uma concepção multilinear.

5. A procura de uma organização da estrutura interna dos segmentos, que levou à elaboração do modelo da geometria de traços.

As orientaçôes teóricas explicitadas em 4. e 5 . estão subjacentes à maioria dos trabalhos em fonologia que presentemente se realizam em Portugal. Importa, contudo, antes de os referir, caracterizar sumariamente essas teorias.

O facto de o modelo da fonologia generativa clássica considerar, por um lado, a formulação das regras como objectivo central da análise e, por outro lado, o segmento - e o nível em que ele se situa - como o domínio

\footnotetext{
${ }^{24}$ Em Viana (1984), a propósito da fricatização e do desvozeamento de consoantes, discutem-se questôes relacionadas com variação e invariância.

${ }^{25}$ Ver adiante a caracterização da teoria auto-segmental e da geometria de traços.

${ }^{26}$ Esta análise foi apresentada em 19983 mas só publicada em 1992, nos Temas de Fonologia.
} 
próprio de aplicação dessas regras impediu o desenvolvimento de mecanismos adequados à análise dos factos prosódicos. As restriçôes do modelo foram emergindo à medida que ele era testado em línguas de natureza muito diferente das línguas românicas e germânicas, evidenciando-se a impossibilidade de tratar, com os instrumentos existentes, traços prosódicos como o tom e a duração. Foi também reconhecida a desvantagem do tratamento do acento exclusivamente a nível segmental, em estrita dependência dos traços fonológicos dos segmentos implicados na sua aplicação. Finalmente, o modelo de 68 revela insuficiências para a análise de constituintes mais vastos do que o segmento, como por exemplo a sílaba, tendo presente que certos processos fonológicos se aplicam nas fronteiras de sílaba e que os instrumentos existentes não eram sensíveis a essas fronteiras. Essas insuficiências provocaram o surgimento da teoria auto-segmental, proposta inicialmente por Goldsmith na procura de resolver problemas postos pela análise das línguas tonais ${ }^{27}$. Nos anos que se seguiram, a teoria alargou o seu domínio de aplicação a outros aspectos da fonologia, como o acento, a harmonização vocálica e a nasalização.

Para responder às exigências da análise fonológica, a teoria propõe a existência de vários níveis autónomos e inter-relacionados por linhas de associação e pela condição de boa formação. Nesses níveis, organizados hierarquicamente, estão situadas as unidades fonológicas - cada um dos traços prosódicos e os segmentos.

Também os traços fonológicos que caracterizam o segmento podem ser estruturados em diversos níveis e manter uma certa autonomia, de modo a persistirem ainda que o segmento a que pertencem seja suprimido. Esta aplicação da teoria auto-segmental aos traços fonológicos, cuja proposta inicial foi apresentada por Clements em $1985^{28}$, recebeu a denominação de geometria de traços. A nova concepção da organização interna dos segmentos veio evidenciar a naturalidade do funcionamento conjunto de certos grupos de traços distintivos na actuação de processos fonológicos. Ainda com relação à identificação dos segmentos deve mencionar-se a dis-

\footnotetext{
${ }^{27}$ Os princípios da fonologia auto-segmental foram apresentados por Goldsmith, pouco tempo após o seu doutoramento, num artigo com o título "The aims of autosegmental phonology", publicado em 1979 em D. Dinnsen (ed.), Current Approaches to Phonological Theory, Bloomington: Indiana University Press, 202-222. Tradução portuguesa em: Mateus e Villalva (eds.): 295-337. ${ }^{28}$ George Clements. The Geometry of Phonological Features. Phonology yearbook 2: 1985: 225252. Ver também George N.Clements e Elizabeth Hume. Internal organization of speech sounds. In John Goldsmith (ed.). The Handbook of Phonological Theory. Cambridge, Mass.: Basil Blackwell, 1995: 245-306.
} 
cussão teórica da noção de subespecificação ${ }^{29}$, que retoma o conceito de marca e propõe mecanismos formais que permitem determinar a incompleta especificação dos segmentos subjacentes.

A teoria auto-segmental e o modelo da geometria de traços têm orientado várias análises recentes da fonologia do português. Uma perspectiva de conjunto das principais questões segmentais e prosódicas encontrase em The phonology of Portuguese, publicada em 2000 por Maria Helena Mateus e Ernesto d'Andrade. Dos mesmos autores existem artigos sobre a estrutura da sílaba em português, sobre a natureza dos seus constituintes e sobre a silabificação de base. A aquisição da sílaba tem sido tratada por Maria João Freitas que desenvolveu igualmente análises sobre os constituintes silábicos e sobre a estrutura dos segmentos que os preenchem. Uma estatística do tipo de sílabas ocorrentes no português, com reflexos na determinação da sílaba canónica, está presente no artigo publicado por Marina Vigário e Isabel Falé.

A estrutura interna dos segmentos fonológicos e a natureza da sua subespecificação são discutidas por Maria Helena Mateus e por Maria Augusta Miguel, integrando-se os trabalhos desta última autora na teoria da regência e do charme ${ }^{30}$. Questões relacionadas com a harmonização vocálica nos verbos e com o processo de nasalização têm sido objecto de análises realizadas por Maria Helena Mateus e Ernesto d'Andrade.

$\mathrm{Na}$ continuação do trabalho sobre o acento de palavra e no enquadramento da perspectiva auto-segmental, Ernesto d'Andrade propóe o modelo da onda rítmica com construção de uma grelha métrica, e Isabel Pereira, ao tratar o acento de palavra, introduz a análise do acento secundário.

A investigação sobre a entoação em português tem uma primeira abordagem, a partir de dados de fonética experimental, no trabalho de Maria do Céu Viana que data de 1987. O levantamento dos padrões entoacionais e a contribuição desses padrões para a estruturação das sequências de fala em português é objecto da dissertação de doutoramento de Ana Isabel Mata, no quadro da análise experimental de dados da fala espontânea.

\footnotetext{
${ }^{29}$ A teoria da subespecificação foi inicialmente desenvolvida por Diana Archangeli em Aspects of Underspecification Theory. Phonology Yearbook 5, 1988: 183-207.

${ }^{30}$ Sobre estas teorias ver, sobretudo, Jonathan Kaye. Phonology: a cognitive view. Hillsdale, N.J.: Lawrence Erlbaum, 1989 e, do mesmo autor, Government in phonology: the case of Moroccan Arabic. Linguistic Review 6:131-160. Ver ainda Monique Charette. Conditions on phonological government, Cambridge: Cambridge University Press, 1991.
} 
Deve-se a Marina Nespor e Irene Vogel uma obra de referência incontornável, publicada em $1986^{31}$ e integrada nos modelos generativos mais recentes que propõe hipóteses gerais para o estudo das unidades entoacionais das línguas. Com o mesmo enquadramento teórico, Marina Vigário e Sónia Frota têm estudado a hierarquia dos constituintes prosódicos em português e têm realizado análises no sentido de caracterizar a palavra fonológica e os sintagmas fonológico e entoacional, e de determinar as fronteiras destes constituintes prosódicos. Questôes de sândi externo, implicadas na análise das fronteiras de constituintes, têm sido tratadas por Marina Vigário. Sónia Frota publicou numerosos estudos sobre o foco fonológico, apresentando hipóteses teóricas do seu funcionamento a partir da identificação e análise do foco na fonologia do português. A contribuição da prosódia para a interpretação sintáctica tem sido tratada por Sónia Frota a propósito da análise do foco fonológico.

A relação entre o léxico e as componentes fonológica e morfológica das línguas, a caracterização da estrutura interna dessas componentes e a interacção das respectivas regras e processos deram origem a uma proposta de organização da gramática em que se devem considerar duas vertentes - a fonológica e a morfológica -, o que permite as duas designaçōes de fonologia lexical e morfologia lexical. Esta teoria foi inicialmente proposta por Kiparsky em $1982^{32}$ e tem sido desenvolvida por Mohanan ${ }^{33} \mathrm{em}$ trabalhos recentes. $\mathrm{O}$ conceito de regras lexicais e pós-lexicais que se aplicam, respectivamente, na componente lexical e na sua saída para a sintaxe é utilizado em análises dos processos e regras fonológicas, sobretudo na obra de Maria Helena Mateus e Ernesto d'Andrade publicada em 2000, e em trabalhos sobre constituintes prosódicos de Marina Vigário e Sónia Frota.

A recente teoria da optimidade teve até agora pouca repercussão nos trabalhos dos linguistas portugueses e apenas Ernesto d'Andrade, em artigo publicado em 1998, a tomou como instrumento de análise na discussão da natureza das glides em português.

A bibliografia apresentada como anexo a este artigo permite avaliar a vitalidade do trabalho que tem sido realizado no domínio da fonologia da língua portuguesa pelos linguistas portugueses.

\footnotetext{
${ }^{31}$ Marina Nespor e Irene Vogel. Prosodic Phonology, Dordrecht: Foris Publications, 1986.

32 Paul Kiparsky. (1982). Lexical Morphology and Phonology. In I-S Yang (ed.). (1982). Linguistics in the Morning Calm, Seoul: Hanshin, 1982: 3-91.

${ }^{33}$ Keneth Mohanan. The Theory of Lexical Phonology. Dordrecht: Reidel, 1986
} 


\section{ANEXo Bibliográfico}

AlmeidA, António (1998) Variação fonética de /1/ em ataque silábico em português europeu. In: MotA / MARQuiLHAS (eds.) 1: 55-76.

ANDRADE, Amália (1987) Um Estudo Experimental das Vogais Anteriores e Recuadas em Português. Implicaçôes para a Teoria dos Traços Distintivos. Dissertação para acesso à categoria de Investigador Auxiliar. Lisboa: Centro de Linguística da Universidade de Lisboa, INIC (publicação policopiada).

(1996b) Alternância vogal/Ø e modificações consonânticas em português europeu. In: DuARTE / Miguel (eds.) 3: 153-186.

(1996a) Reflexōes sobre o 'e mudo' em português europeu. In: DuARTE / Leiria (eds.) 2: 303-344.

(1994) Estudo acústico de sequências de oclusivas em português europeu. Actas do $9^{\circ}$ Encontro Nacional da APL. Coimbra: Colibri. 1993: $1-15$.

(1992b) Ainda as vogais de Sagres. Estudo fonético da distinção recuado/não recuado. Actas do $8^{\circ}$ Encontro Nacional da APL. Coimbra: 37-58.

(1992a) Reflexôes sobre as distinçôes de "altura" em português. Workshop sobre o Português. Lisboa: Associação Portuguesa de Linguística (publicação policopiada).

(1976) The Portuguese nasal vowels: phonetics and phonemics. In: Schmidt-Radefeldt (ed.) Readings in Portuguese Linguistics. Amsterdam: North-Holland Publishing Comp.: 349-396.

\& Mascarenhas, Isabel (1996) Para um estudo do vozeamento em início de vogal diante de consoante oclusiva. In: DUARTE / LEIRIA (eds.) 3: 529-546.

(1995) Sobre a variação fonética de /i/ - uma primeira abordagem. Actas do $10^{\circ}$ Encontro Nacional da APL. Évora: Colibri: 25-44.

AndRADE PARDAL, Ernesto d' (1999) O papel da sonoridade da sílaba em português. Actas do $14^{\circ}$ Encontro Nacional da APL. Lisboa: 99-116.

(1997a) Sobre a alternância vogal/glide em português. In: MоTA / MARQUILHAS (eds.), vol. I: 91-102.

(1997b) Some remarks about stress in Portuguese. In: MARTínEZGil e Morales-Front (eds.) Issues in the Phonology and Morphology of the Major Iberian Languages. Washington: Georgetown University Press: 343-358. 
(1996) A fonologia pós-SPE. In: FARIA et al. (eds.): 201-211. (1996). The syllable structure in Portuguese. The Phonology in the World's Languages. OUP: Pezenas.

(1994a) Algumas particularidades do português falado no Funchal. Actas do $9^{\circ}$ Encontro Nacional da APL: 17-30

(1994b) Na onda do acento. In: DuARTE / LeIRIA (eds.) 1: 157-174.

(1993) Dicionário Inverso do Português. Lisboa: Cosmos.

(1992a) Word stress in Portuguese. Colóquio sobre Linguística Portuguesa. Lisboa: GLOW

(1992b) Temas de Fonologia. Lisboa: Colibri.

(1984) Sobre os plurais em galego. Boletim de Filologia 29: 173.180 (1981) Sobre a alternância vocálica em português. Boletim de Filologia 26: 70-81.

(1979) A classificação das vogais e a diacronia. Boletim de Filologia 25: $21-5$.

(1977) Aspects de la Phonologie (Générative) du Portugais. Lisboa:

Centro de Linguística da Universidade de Lisboa, INIC.

\& KinM, Alain (1988) Fonologia auto-segmental e nasais em português. Actas do $3^{\circ}$ Encontro Nacional da APL. Lisboa, 1987: 51-60.

Andrade, Ernesto d' \& LaKs, Bernard (1996a) Stress and Constituency: the case of Portuguese. In: Durand, Jacques e LAKS, Bernard (eds.) Current Trends in Phonology: Models and Methods. ESRI. Manchester: Universidade de Salford, vol. I: 15-41.

(1992) $\mathrm{Na}$ crista da onda: o acento de palavra em português. Actas do $7^{\circ}$ Encontro Nacional da APL. Lisboa, 1991: 15-26.

(1988) Fonologia métrica e análise aritmética da quantidade. Actas do $3^{\circ}$ Encontro Nacional da APL, Lisboa, 1987: 39-50.

Andrade, Ernesto d' \& Rodrigues, Maria Celeste (1998). Das escolas e da cultura: história de uma sequência consonântica. Actas do $14^{\circ}$ Encontro Nacional da APL. Lisboa: 117-133.

Andrade, Ernesto d' \& Viana, Maria do Céu (1994) Sinérese, diérese e estrutura silábica. Actas do $9^{\circ}$ Encontro Nacional da APL, Lisboa, 1993: 31-42.

(1993a) Que horas são às (1)3 e 15?. Actas do $8^{\circ}$ Encontro Nacional da APL, Lisboa, 1992: 59-66.

(1993b) As sobrodas da translineação. Actas do $1^{\circ}$ Encontro de Processamento da Lingua Portuguesa escrita e falada, Lisboa: Fundação Calouste Gulbenkian: 208-214 (publicação policopiada). 
(1989) Ainda sobre o acento e o ritmo em português. Actas do $4^{o}$ Encontro Nacional da APL, Lisboa, 1988: 3-16.

(1988). O ritmo e o acento em português. Actas do $2^{\circ}$ Encontro Regional da APL, Lisboa (a publicar).

Andrade, Ernesto d', Viana, Maria do Céu, Oliveira, L. \& Trancoso, Isabel (1993). Uma questão de equilíbrio. Actas do $8^{\circ}$ Encontro Nacional da APL, Lisboa: 523-534.

BarbeIro, Luís Filipe (1986) Estrutura Silábica do Português. O Papel da Silaba na Análise dos Processos Fonológicos e Fonéticos. Dissertação de mestrado. Lisboa: Faculdade de Letras da Universidade de Lisboa.

BARbOSA, Jorge Morais (1994) Introdução ao Estudo da Fonologia e Morfologia do Português. Coimbra: Almedina.

(1994) Introdução ao Estudo da Fonologia e Morfologia do Português. Coimbra: Almedina.

(1988) Notas sobre a pronúncia portuguesa nos últimos cem anos. Biblos 64: 329-382.

(1983) Études de Phonologie Portugaise. Évora: Universidade de Évora [Lisboa: Junta de Investigaçōes Científicas do Ultramar, $\left.{ }^{1} 1965\right]$.

Cabral, Vasco \& Delgado-Martins, Maria Raquel (1993) Percepção e hierarquia de traços. Actas do $8^{\circ}$ Encontro Nacional da APL. Lisboa, 1992: 67-78.

(1980). A percepção da fala: alguns dados experimentais sobre as consoantes do português. Revista Portuguesa de Psicologia, vol. 14/16: 129-166.

CarvalHo, Joaquim Brandão de. (1989a) L'évolution des sonantes ibéroromanes et la chute de $-\mathrm{n}-,-\mathrm{l}$ - en galaico-portugais. Revue de Linguistique Romane 53: 159-188.

(1989b). L'origine de la terminaison -ão du portugais: une approche phonétique nouvelle du problème. Zeitrischrift für Romanische Phonologie 105:148:160.

(1989c) Phonological Conditions on the Portuguese Clitic Placement: on syntactic evidence for stress and rhythmical patterns. Linguistics, 27: 405-436.

(1988a) Évolution phonologique, interférences grammaticales et aérologie: à propos des résultats de -ANU/-ANA en galicien. Vox Romanica 47: 184-198.

(1988b) Nasalité et structure syllabique en portugais et en galicien: approche non linéaire et panchronique d'un problème phonologique. Verba 15: 237-263. 
Castro, Ivo (1991) Curso de História da Lingua Portuguesa. Lisboa: Universidade Aberta

Castro, Ivo \& Leiria, Isabel (1987) A Demanda da Ortografia Portuguesa. Comentário do Acordo Ortográfico de 1986 e Subsídios para a Questão que se the Seguiu. Lisboa: Edições João Sá da Costa.

Castro, Ivo (ed.) (1997). Actas do $12^{\circ}$ Encontro Nacional da APL. Lisboa: Colibri.

Cintra, Luís Filipe Lindley (1983) Estudos de Dialectologia Portuguesa. Lisboa: Sá da Costa Editora.

(1971) Nova proposta de classificação dos dialectos galego-portugueses. Boletim de Filologia 22: 81-116.

Costa, J. e FreitAs, M. J. (1999) 'V e CV como estruturas não marcadas: evidência da aquisição do Português Europeu'. In Actas do $14^{\circ}$ Encontro Nacional da APL. Braga: APL.

(no prelo) 'Sobre a representação da nasalidade em Português Europeu: evidência dos dados da aquisição'. In: Hernandorena, C. (org). Aquisição de Lingua Materna e de Lingua Estrangeira - aspectos fonético-fonológicos. Pelotas: ALAB/EDUCAT.

Cruz-Ferreira, Maria Madalena (1985) Elementos para um estudo comparativo dos sistemas prosódicos do português e do inglês. Miscelânea de Estudos Dedicados a Fernando de Mello Moser. Lisboa: Faculdade de Letras da Universidade de Lisboa: 373-388

(1983) Non-native Comprehension of Intonation Patterns in Portuguese and in English. Dissertação de doutoramento. Manchester: Universidade de Manchester

Delgado-Martins, Maria Raquel (1996) Relação fonética/fonologia: a propósito do sistema vocálico do português. In: Duarte / Leiria (eds.), vol. I: 311-326.

(1989) Contributions à une théorie de la perception de l'accent et de l'intonation en portugais. In: Bothorel, André, Galdin, JeanClaude, Wioland, François e Zerting, Jean-Pierre (1989). Mélanges de Phonétique Générale et Experimentale Offerts à Péla Simon. Strasbourg: Publications de l'Institut de Phonétique de Strasbourg: 313-319.

(1988) Ouvir falar: Introdução à Fonética do Português. Lisboa: Caminho. (1983) Sept Études sur la Perception. Lisboa: Publicações do Laboratório de Fonética da Faculdade de Letras.

(1982) Aspects de l'Accent en Portugais. Voyelles Toniques et Atones. Hamburg: Buske. 
(1976) Vogais e consoantes do português: estatística de ocorrência, duração e intensidade. Boletim de Filologia 24: 1-11.

1973) Análise acústica das vogais tónicas em: português. Boletim de Filologia 22: 303-314

Delgado-Martins, Maria Raquel \& Freitas, Maria João (1992) Contributo para a identificação de elementos estruturadores da entoação na leitura. Actas do $7^{\circ}$ Encontro Nacional da APL, 1991, Lisboa: 255-270

(1991). Temporal structure of speech: "reading news on TV". Proceedings of the ESCA Workshop on Phonetics and Phonology of speaking styles. Barcelona.

Delgado-Martins, Maria Raquel, Harmegnies, Bernard \& Poch, Dolors, (1996). Changement phonétique en cours du Portugais Européen. In: DuARTE / Miguel (eds.), vol. III: 249-260.

DuARTE, Inês \& LeIRIA, Isabel (eds.) (1996) Actas do Congresso Internacional sobre o Português, 1994, Lisboa: Colibri.

Duarte, Inês \& Miguel, Matilde (eds.) (1996). Actas do $11^{\circ}$ Encontro Nacional da APL, vol. III, 1995, Lisboa: Colibri.

Ellison, Mark \& Viana, Maria do Céu (1995) Antagonismo e elisão de vogais átonas finais em: português europeu. In: DuARTE / Miguel (eds.): 261-282.

FALCÃo GonçALVEs, Patrícia (1984) A propósito de Articulator Features and Portuguese Vowel Height. Boletim de Filologia 29 (vol. 2): 355-382.

FALCÃO, Patrícia (1985) Relaçôes entre Fonética e Fonologia no Quadro Teórico da Gramática Generativa Standard. Dissertação de mestrado. Lisboa: Faculdade de Letras da Universidade de Lisboa.

FALÉ, Isabel (1997) Duração das vogais tónicas e fronteiras prosódicas: uma análise em estruturas coordenadas. In: Mota / MARQUILHAS (eds.): 255-270.

(1995) Fragmentos da Prosódia do Português Europeu: as Estruturas Coordenadas. Dissertação de mestrado, Lisboa: Faculdade de Letras da Universidade de Lisboa.

FARIA, Isabel Hub / PEDRO, Emília / DuARTE, Inês / Gouveia, Carlos (eds.) (1996) Introdução à Linguistica Geral e Portuguesa. Lisboa: Caminho.

FERrEIRA, Valentina (1975) A alternância vocálica dos verbos portugueses: análise em fonologia generativa natural. Actas do $1^{\circ}$ Encontro para a Investigação e Ensino do Português, vol. 1:365-375.

Figueira, M. Luísa, Faria, I. H., Viana, M. C., Frota, S. e Andrade, A. (1990) Effects of cloxazolam on the temporal organization of speech 
in chronic paranoid schizophrenic patients. Acta Psiquiátrica Portuguesa, Vol. 36, 69-75.

Fikkert, Paula e Freitas, Maria João (1998). 'Acquisition of syllable structure constraints: evidence from Dutch and Portuguese'. Proceedings of GALA'97 (Generative Approaches to Language Acquisition). Edinburgh: University of Edinburgh.

Freitas, Maria João (1998a) Os segmentos que estão nas sílabas que as crianças produzem: localidade silábica e hierarquia de aquisição. In: Mota / MARquilhas (eds.): 303-324..

(1997) Aquisição da Estrutura Silábica do Português Europeu. Dissertação de doutoramento. Lisboa: Universidade de Lisboa.

(1995b) Alveolar trill(ions of problems). evidence from children acquiring European Portuguese syllables. In: FARIA, Isabel e FreITAS, Maria João (eds.) Studies on the Acquisition of Portuguese. Lisboa: APL; Colibri.

(1995a) Uma questão de ataque silábico nas primeiras palavras. In: DuARTE / Miguel (eds.): 283-296.

(1993) Sílaba e desenvolvimento fonológico: questōes preliminares. Revista Internacional da Lingua Portuguesa 10: 97-108.

(1992) Contributo para o estudo de padrões de estruturação temporal da fala no português europeu. In: Pereira, Mata e Freitas (eds.): 77-103.

(1988) Elementos para um estudo do tempo real no discurso. Actas do $3^{\circ}$ Encontro Nacional da APL. Lisboa: 229-244.

(1987) Estratégias de Organização Temporal do Discurso em Português. Dissertação de mestrado. Lisboa: Faculdade de Letras da Universidade de Lisboa.

Freitas, M. J. (2000) 'O grupo consonântico 's+C' em início de palavra: evidência da aquisição do Português Europeu'. Actas do $15^{\circ}$ Encontro Nacional da APL. Faro: APL Freitas,

FreITAS, M. J. (1999) 'Estatutos das consoantes que fecham sílabas no Português Europeu: evidência dos dados da aquisição'. In: Actas do $14^{\circ}$ Encontro Nacional da APL. Braga: APL.

. (no prelo) 'Pratos, patos e p[I] ratos: o caso da aquisição dos Ataques complexos em Português Europeu'. In: Homenagem à Professora Henriqueta Costa Campos, Revista da FCSH-UNL.

(no prelo) 'Syllabic constituency and segmental emergence: Evidence from the acquisition of European Portuguese'. In: Proceedings 
of VIIIth International Congress for the Study of Child Language. Sommerville: Cascadilla Press.

(no prelo) 'Os pinguins são diferentes dos coelhos? Questões sobre oclusivas velares, semivogais e arredondamentos na aquisição do Português Europeu'. Actas do $16^{\circ}$ Encontro Nacional da APL. Lisboa: APL.

. (no prelo) 'Os sons de ataque: segmentos, segmentos complexos e grupos segmentais na aquisição do Português Europeu'. Anais do V Encontro Nacional de Aquisição da Linguagem. Porto Alegre: EDIPUCRS. \& Miguel, Matilde (1998b) 'Prosodic and syntactic interaction: the acquisition of NP functional projections in European Portuguese'. In: Proceedings of ConSOLE6. Leiden: ConSOLE.

Freitas, M. J. \& FARIA, I. (1999). 'Order of acquisition for syllable structure: evidence from Portuguese children'. In: Proceedings of ISAPL'97. Porto: Faculdade de Letras da Universidade do Porto.

Freitas, Maria João, Miguel, Matilde \& Faria, Isabel (2001) 'Interaction between Prosody and Morphosyntax: plurals within codas in the acquisition of European Portuguese'. In: B. Hoehle e J. Weissenborn (eds) Proceedings of 'How to Get into Language: Approaches to Bootstrapping in Early Development'. Amsterdam: John Benjamins Publishers.

Frota, Sónia (2001) Nuclear falls and rises in European Portuguese: a phonological analysis of declarative and question intonation. A aparecer em Probus Special Issue on Intonation in Romance.

(2000a) Prosody and Focus in European Portuguese. Phonological Phrasing and Intonation. New York: Garland Publishing.

(2000b) On the Phonology of Focus in European Portuguese. Comunicação apresentada no GLOW Focus Workshop, University of Deusto, Bilbao.

(2000c) Questões de associação e alinhamento tonal: implicações para uma teoria da entoação. Actas do $15^{\circ}$ Encontro Nacional da APL. Rui V. Castro and Pilar Barbosa (eds) Vol.1, 513-532. Coimbra: APL (2000d) Tonal association and target alignment in European Portuguese nuclear falls. A aparecer em Papers in Laboratory Phonolgy VII, Natasha Warner and Carlos Gussenhoven (eds) Cambridge: Cambridge University Press.

(1997a) On the prosody and intonation of Focus in European Portuguese. In: Martínez-Gil e Morales-Front (eds.) Issues in the Phonology and Morphology of the Major Iberian Languages. Washington: Georgetown University Press: 359-392. 
(1997b) Focus and Phrasing, Stress and Accent in European Portuguese. In: MATOs, Gabriela (ed.) Interfaces in Linguistic Theory. Lisboa: APL; Colibri: 177-200.

(1997c) Association, Alignment and Meaning: the tonal sequence HL and Focus in European Portuguese. In: Botinis, Antonis et al. (eds.) Intonation: Theory, Models and Applications - Proceedings of an ESCA Workshop. Atenas: ESCA; Universidade de Atenas: 127-130.

(1996) Prosodic phrases and European Portuguese: in search of evidence. In: Antonietta Bisetti et al. (eds.) Proceedings of ConSOLE III, Leiden: SOLE: 47-69.

(1995b). Clashes and Prosodic Domains in EP. Proceedings 19. Institute of Phonetic Sciences. University of Amsterdam: 93-107.

(1995) Os domínios prosódicos e o português europeu: fenómenos de sandhi. Actas do $10^{\circ}$ Encontro Nacional da APL. Évora, 1994: 221-238.

(1994a) Aspectos da prosódia do português europeu. In: Bisol (ed.) Fonologia: Análises não-lineares. Letras de Hoje 98. Porto Alegre: 77-99.

(1994b) Is Focus a phonological category in Portuguese? In: Ackema, P. e Schoorlemmer, M. (eds.) Proceedings of ConSOLE I. The Hague: Holland Academic Graphics: 69-86.

(1994c) Recensões a M.B. Abaurre e L. Wetzels (orgs.) Cadernos de Estudos Linguisticos, no 23, Jul/Dez 1992, Unicamp, Campinas e M. M. Machado (org.) Cadernos de Estudos Linguísticos, no 25, Jul/Dez 1993, Unicamp, Campinas. In: Revista Internacional de Lingua Portuguesa ${ }^{\circ}$ 12, Lisboa: AULP: 182-183.

(1993a) On the prosody of focus in European Portuguese. Proceedings of the Workshop on Phonology. Coimbra: 45-66 (publ. policop.). (1993b) A prosódia do advérbio na frase. Interacção e convergência. Actas do $8^{\circ}$ Encontro Nacional da APL. Lisboa, 1992: 204-224.

(1991) Para a Prosódia da Frase: Quantificador, Advérbio e Marcação Prosódica. Dissertação de mestrado. Lisboa: Faculdade de Letras da Universidade de Lisboa.

Frota, Sónia e Jorge, Guilhermina (1989) Para um estudo da organização temporal no discurso de um esquizofrénico paranóide crónico. Actas do $4^{\circ}$ Encontro da APL. FLUL: 281-303.

Frota, Sónia e VigÁrio, Marina (2000a) Aspectos de prosódia comparada: ritmo e entoação no PE e no PB. Actas do $15^{\circ}$ Encontro Nacional da APL. Rui V. Castro and Pilar Barbosa (eds), vol.1: 533-555. Coimbra: APL. 
(2000b) On the correlates of rhythmic distinctions: the Euroepan/ Brazilian Portuguese case. Poster apresentado na $7^{\text {th }}$ Conference on Laboratory Phonology, University of Nijmegen. (1993) Aquisição da Prosódia - II: Categorias, Evolução e Interacção. Análise Psicológica , 4 (XI): 531-555.

(a aparecer) Efeitos de peso no Português Europeu. In: Homenagem à Professora Henriqueta Costa Campos. Revista da FCSH-UNL.

(1996) On Weight Effects in European Portuguese. Glow Worshop on Weight Effects. Atenas.

(1995) The Intonation of one European Portuguese Infant: a First Approach. In: Faria, Isabel e Freitas, Maria João (eds.) Studies on the Acquisition of Portuguese. Lisboa: APL; Colibri: 17-34.

LACERDA, Armando (1970 e 1975) Objectos verbais e significado elocucional.

Toemas e entoemas. Entoação. Sep. da Revista do Laboratório de Fonética Experimental, 7 e 8, Coimbra.

LeIte, Fernando (1997) Vogais silenciosas? In: CASTRO (ed.): 157-164. MARÇALO, Maria João (1995) A flutuação dos fonemas em português. Uma questão de morfologia? Actas do $10^{\circ}$ Encontro Nacional da APL: 255-268.

(1992) O círculo linguístico de Praga e a concepção de fonema. Actas do $7^{\circ}$ Encontro Nacional da APL: 202-210.

MAIA, Clarinda de Azevedo (1996) O galego-português medieval: sua especificidade no contexto dos romances peninsulares e futura diferenciação do galego e do português. In: DuARTE e LEIRIA (eds.) vol. I. Lisboa: Colibri, 33-51.

(1986) História do galego-português. Estado linguístico da Galiza e do Noroeste de Portugal do século XIII ao século XVI (com referência à situação do galego moderno). Coimbra: INIC.

Martins, Ana Maria (1999) Ainda 'os mais antigos textos escritos em português’. Documentos de 1175 a 1252. In: FARIA (org.): $491-534$.

.(1995) A evolução das vogais finais ã, ô, e) no português. Miscelânea de Estudos Linguísticos, Filológicos e Literários in Memoriam de Celso Cunha. Rio de Janeiro: Nova Fronteira: 617-646.

Martins, Fernando (1995) Modelo de Reconhecimento de Fala para a Lingua Portuguesa: as Invariantes Fonéticas e a Programação por Objectos. Dissertação de doutoramento. Lisboa: Universidade de Lisboa.

(1986) Entoação e Organização do Enunciado. Dissertação de mestrado. Lisboa: Faculdade de Letras da Universidade de Lisboa. 
Mascarenhas, Maria Isabel (1996) Estudo da Variação Dialectal entre Lisboa e Porto das Vogais Atonas [-rec] e [+arr] em contexto inicial. Dissertação de mestrado. Lisboa: Faculdade de Letras da Universidade de Lisboa. Mata Da Silva, Ana Isabel (1990) Questôes de Entoação e Interrogação em Português. "Isso é uma Pergunta?". Dissertação de mestrado. Lisboa: Faculdade de Letras da Universidade de Lisboa.

(1987) Ditongos crescentes do português: análise acústica. Actas do $3^{\circ}$ Encontro Nacional da APL. Lisboa: 379-400.

MATA, Ana Isabel (1992) A questão da entoação na interrogação em português. "Isso é uma pergunta?". In: Pereira, Mata e Freitas: 33-74.

\& Pereira, Isabel (1992) Flexibilidade de contornos entoacionais em sequências de natureza interrogativa: percepção e interpretação. Actas do $7^{\circ}$ Encontro Nacional da APL. Lisboa:

Mateus, Maria Helena Mira (1998) Ainda a subespecificação na fonologia do português. In: Mota / MarquilHas (eds.): 63-74.

(1997a) Redundâncias lexicais e subespecificação: o sistema do português. In: CASTRO (ed.): 203-214.

(1997b) Aspectos da fonologia lexical do Português. In: BRITO, A. M. et al (eds.) Sentido que a Vida Faz. Estudos para Óscar Lopes. Porto: Campo das Letras: 7-22

(1996a) Factos prosódicos nas gramáticas portuguesas. Actas do $11^{\circ}$ Encontro Nacional da APL. Lisboa, (1995): 123-142. (1996a)

Factos prosódicos nas gramáticas portuguesas. Actas do $11^{\circ}$ Encontro Nacional da APL. Lisboa, (1995): 123-142.

(1996b) Fonologia. In: FARIA et al. (eds.): 171-199.

(1996c) O português: caminhos da investigação. In: DuARTE e LEIRIA (eds.) Lisboa: 7-22. (1996c) O português: caminhos da investigação. In: Duarte e Leiria (eds.) Lisboa: 7-22.

(1994) A silabificação de base em português. Actas do $10^{\circ}$ Encontro Nacional da APL. Évora: 289-300.

(1993) Onset of Portuguese Syllables and Rising Diphthongs. Proceedings of the Workshop on Phonology. Coimbra: 93-104.

(1987) L'harmonie vocalique en Portugais. Revue Européenne des Sciences Sociales, 25 (=Hommage à Jean-Blaise Grize): 225-230.

(1984) Fonologia do Galego e do Português. Actas do I Congresso Internacional da Lingua Galego-Portuguesa na Galiza. Ourense: 295-304. (1993) Onset of Portuguese Syllables and Rising Diphthongs. Proceedings of the Workshop on Phonology. Coimbra: 93-104. 
(1982) Aspectos da Fonologia Portuguesa. Lisboa: INIC (Textos de Linguística, 6) [Lisboa: Centro de Estudos Filológicos, ${ }^{1} 1975$ ]. (1982) O acento da palavra em português: uma nova proposta. Boletim de Filologia, 28: 211-229.

(1976) The Portuguese perfect indicative: a generative approach. In: Schmidt-Radefeldt (ed.) Readings in Portuguese Linguistcs. Amsterdam: North-Holland Publishing Comp.: 397-424.

Mateus, Maria Helena Mira \& Delgado-Martins, Maria Raquel (1982) Contribuição para o estudo das vogais átonas ["] e [u] no português europeu. Biblos 58: 111-128.

Mateus, Maria Helena Mira, Vilalva, Alina, (eds.) (1985) Novas Perspectivas em Fonologia: Organização e Introdução. Lisboa: Laboratório de Fonética da Faculdade de Letras de Lisboa.

Mateus, Maria Helena Mira, Viana, Amália Andrade \& Vilalva, Alina, (1991) Fonética, Fonologia e Morfologia do Português. Lisboa: Universidade Aberta.

Mateus, Maria Helena Mira, Andrade, Ernesto d' (2000) The Phonology of Portuguese. Oxford: Oxford University Press.

(1998) The syllable structure in European Portuguese. D.E.L.T.A 14/1: 13-32, S. Paulo.

Matos, Gabriela, Miguel, Matilde, Freitas, Maria João e Faria, Isabel (1998) 'Functional Categories in early acquisition of European Portuguese'. In: Proceedings of GALA'97 (Generative Approaches to Language Acquisition). Edinburgh: University of Edinburgh.

Miguel, Maria Augusta Cavaco (1999) O Acento de Palavra em Portuguêsuma Análise Métrica. Dissertação de doutoramento. Coimbra: Faculdade de Letras da Universidade de Coimbra.

(1994) Interpretação fonológica de alguns plurais em português. Actas do $10^{\circ}$ Encontro Nacional da APL. Évora: 331-340.

(1993) Os Padrões das Alternâncias Vocálicas e da VogalZero na Fonologia Portuguesa. Dissertação de doutoramento. Ponta Delgada: Universidade dos Açores.

(1993) Heavy diphthongs: a phonological view. Proceedings of the Workshop on Phonology. Coimbra: 105-114.

(1990) As consoantes R/r na cadeia silábica. Actas do $\sigma^{\circ}$ Encontro $\mathrm{Na}$ cional da APL: 229-238. Porto.

(1989) Alternância da vogal fria com a vogal zero em núcleos pretónicos. Actas do $5^{\circ}$ Encontro Nacional da APL. 119-126 Lisboa:. 
Mota, Maria Antónia \& Marquilhas, Rita, (eds.) (1998) Actas do $13^{\circ}$ Encontro Nacional da APL, 1997. Colibri Lisboa:.

Pereira, Isabel (1998) A regra do acento em português e o seu lugar na gramática. Comunicação apresentada no $13^{\circ}$ Encontro Nacional da APL. Lisboa.

(1997) O acento latino e o acento em português: do troqueu moraico ao troqueu silábico. In: CASTRO (ed.): 269-276. (1993) Grid-only versus constituency in the study of stress in Portuguese. Proceedings of the Workshop on Phonology. Coimbra: 115-125. (1992) Panorama das abordagens linguísticas das questões prosódicas. In: Pereira, Mata e Freitas: 3-32.

(1992) Questôes de acento. Actas do $8^{\circ}$ Encontro Nacional da APL. Lisboa: 418-430.

(1990) Da Prosódia: Análise da Evolução do Conceito de Prosódia e das Diferentes Abordagens Linguisticas das Questôes Prosódicas. Dissertação de mestrado. Lisboa: Faculdade de Letras da Universidade de Lisboa.

PEREIRA, Isabel \& FreitAs, Maria João (1989) Valores do silêncio: contributo para o estudo da pausa na delimitação do grupo entoacional em português. Actas do $5^{\circ}$ Encontro Nacional da APL: 171-186, . Lisboa .

Pereira, Isabel \& Mata, Ana Isabel, \& Freitas, Maria João (1992) Estudos em Prosódia. Lisboa: Colibri.

PInTo, Adelina Angélica (1981) A africada c\& em português: estudo sincrónico e diacrónico. Boletim de Filologia 26: 139-192.

(1980) A neutralização da oposição fonológica $\mathrm{v} / \mathrm{b}$ em português. Biblos 56: 599-653.

Rio-TorTo, Graça (1998) Fonética, Fonologia e Morfologia do Português. Lisboa: Colibri.

Rodrigues, Maria Celeste \& Rodrigues, Maria Celeste, (2001) Lisboa e Braga: Fonologia e Variação. Dissertação de doutoramento. Lisboa: Universidade de Lisboa.

(2000) Novos dados acerca de /\#OSC/. Actas do $15^{\circ}$ Encontro Nacional da APL. Faro: 287-300.

Rodrigues, Maria Celeste \& Martins, Fernando (2000) Espaço acústico das vogais acentuadas de Braga. Actas do $15^{\circ}$ Encontro Nacional da APL. Faro: 301-316.

SANTOS, Isabel Almeida (1997) Fenómenos de palatalização vocálica na România: valor dialectal em território português (continental). Actas do $12^{\circ}$ Encontro Nacional da APL, vol. II, Braga: 273-287. 
Viana, Maria do Céu (1987) Para a Sintese da Entoação do Português.

Dissertação para acesso à categoria de investigador auxiliar. Lisboa: Centro de Linguística da Universidade de Lisboa, INIC (publicação policopiada).

(1984) Étude de deux aspects du consonantisme du Portugais: fricatisation et dévoisement. Dissertação de 'Doctorat de 3ème cycle', Strasbourg: Université de Strasbourg

(1979) O índice duração e a análise acústica das oclusivas orais em português. Boletim de Filologia 25: 1-19.

Andrade, E. d', Oliveira, L., Trancoso, I.(1992) Uma questão de equilíbrio. Actas do $8^{\circ}$ Encontro Nacional da APL, Lisboa: 523-534.

MARQues, G. \& SiLva, F.(1996) Sobre a pronúncia de nomes próprios, siglas e acrónimos em português europeu. In: DuARTE / LEIRIA (eds.) vol. III. Lisboa: 481-520.

Vigário, Marina (1998) Aspectos da Prosódia do Português Europeu: Estruturas com Advérbios de Exclusão e Negação Frásica. Universidade do Minho: Centro de Estudos Humanísticos.

VigáRIO, Marina (1998). Elisão da vogal não-recuada final e a palavra prosódica no português europeu. In Mota / MARQuilHAS (eds.): 359376.

(1997) Marcação prosódica em frases negativas no português europeu. In: CASTRO (ed.): 329-349.

(1997) Processos de desambiguação prosódica em estruturas com advérbios de exclusão. In: BRITO, A.M. et al. (eds.) Sentido que a Vida faz. Estudos para Óscar Lopes. Porto: Campo das Letras: 855-868.

(199) Pronominal cliticization in European Portuguese: a postlexical operation. Catalan Working Papers in Linguistics: 219-237.

\& Falé, Isabel (1993). A sílaba do Português Fundamental: uma descrição e algumas considerações de ordem teórica. Actas do $9^{\circ}$ Encontro Nacional da APL. Coimbra: 465-478.

VigÁrio, Marina e Frota, Sónia (1993) Aspectos da Aquisição da Prosódia do Português. Actas do EPLP'93 - $1^{\circ}$ Encontro de Processamento da Lingua Portuguesa Escrita e Falada. Lisboa, 203-208.

(1992) Aquisição da Prosódia - I : Uma categorização das produções sonoras de e para a criança. Análise Psicológica , 4 (X): 457-478. 